\title{
Natural History of 11 Cases of Twin-twin Transfusion Syndrome Without Intervention
}

\author{
Ahmet Gul, Halil Aslan, Ibrahim Polat, Altan Cebeci, Hasan Bulut, Ozturk Sahin, and Yavuz Ceylan \\ Department of Obstetrics and Gynecology, Istanbul SSK Bakirkoy Maternity and Children Hospital, Istanbul, Turkey
}

\begin{abstract}
he natural history of 11 cases of twin-twin transfusion syndrome (TTTS) in monochorionic diamniotic (MCDA) twin pregnancies has been reviewed. Seven cases before 28 weeks and four pregnancies after 28 weeks had been followed up without intervention. Eight cases had premature uterine contractions. All seven pregnancies before 28 weeks aborted, leading to a $100 \%$ mortality rate. After 28 weeks all mothers delivered live births. The diagnosis of TTTS before 28 weeks, and with premature uterine contraction, seems to be a poor prognostic sign.
\end{abstract}

Twins are found in about $2 \%$ of pregnancies and $20 \%$ of twins are monochorionic (Derom et al., 1996). In monochorionic diamniotic (MCDA) twin pregnancies, development of acute polyhydramnios - oligohydramnios sequence has been presumed as twin - twin transfusion syndrome (TTTS) and is associated with a high perinatal mortality rate, primarily because of spontaneous abortion or delivery of very premature babies. It affects $10-30 \%$ of MCDA twin pregnancies (Bajoria et al., 1995) and up to $100 \%$ perinatal mortality has been reported unless treated (Elejalde et al., 1983; Saunders et al., 1992; Weir et al., 1979; Witmann et al., 1981). Since prenatal diagnosis of TTTS by ultrasound became possible (Wittmann et al., 1981), several treatment methods have been developed such as amniodrenage, septostomy, laser ablation, cord occlusion and gradually increased survival rates have been reported in the past 15 years (Johnson et al., 2001; Mari et al., 2001; Quintero et al., 2001; Saunders et al., 1992). This increased survival rate is not clearly understood and while only investigating a small number of cases, Skupski et al. (2002) did not find a significant difference between treatment and control groups. During this time it was found that improvements in neonatal care and different diagnostic criteria might impact on the survival rates. To clarify results of treatment, we need to know the natural history of TTTS cases and the results of randomised studies. In this study, we aimed to determine the natural pregnancy outcome in eleven cases.

\section{Materials and Method}

Istanbul SSK Bakirkoy Maternity and Children Hospital is a tertiary referral centre for fetal diagnosis and therapy and has 22,000 deliveries per year. During a 4-year period (1998 to 2001) 11 cases of TTTS were followed without intervention out of $21 \mathrm{MCDA}$ twin pregnancies with polyhydramnios - oligohydramnios sequence, referred to the perinatal medicine unit for prenatal diagnosis, and reviewed retrospectively. It is noted that 15 of 21 TTTS cases were referred or admitted due to uterine contraction and did not have regular prenatal follow-up. The requirements for diagnosis of TTTS are MCDA placentation, polyhydramnios (largest vertical pocket $>8 \mathrm{~cm}$ ) in one sac and oligohydramnios (largest vertical pocket $<2 \mathrm{~cm}$ ) in the other. Pregnancies with congenital anomalies were excluded. The cases with tocolytic treatment for preterm labour at admission were followed without intervention. The parents were counseled as to the likely poor prognosis and offered the options of conservative management or amniodrenage if the condition of the case allowed it. Cases in which parents declined amniodrenage and cases with preterm labour were referred to as natural outcome. All placentae after delivery or abortion were reviewed for chorionicity. Survival rate, admission to neonatal care unit at delivery and postnatal (6 to 18 months of age) data relating to neurological outcome collected from family and pediatrician of the case were sought in all survivors.

\section{Results}

For the 11 patients who were followed without intervention, the gestation at diagnosis, interval of diagnosis to delivery and outcome of pregnancies are summarized in Table 1.

All cases had polyhydramniosis/oligohydramniosis sequence and all donor twins were "stuck twins". Postpartum exam confirmed that all had MCDA placentation. Eight cases (case 1 to 8 ) at admission had premature uterine contractions and we begun tocolytic treatment. Mean gestation at diagnosis was $26^{+5}$ weeks (range 21-33) and diagnosis to delivery was six days (range 1-17). Diagnosis of TTTS in seven cases out of 11 was before 28 weeks and all aborted. Four cases (case 8 to 11 ) in $31,32,33,34$ weeks, that had abdominal delivery because of fetal distress, delivered six live births. One case (case 5) in which the recipient had hydrops fetalis aborted one day after admission.

Another 10 cases had serial amniocentesis (see Table 2). The mean gestation at diagnosis was 25 weeks (range 19 to 34). Seven of 10 cases at diagnosis had premature labour and had tocolytic treatment. Amniocenteses were performed one to three times $($ mean $=2)$ with the average

Address for correspondence: Ahmet Gul, M.D., Gencler Cad., No.30/ 2, Bakirkoy,34740 Istanbul,Turkey.Email: ahmetgul@ttnet.net.tr 
Table 1

The Cases of TTTS at Diagnosis, Interval of Diagnosis to Delivery and Fetal Outcome Without Intervention

\begin{tabular}{lccccc}
\hline Case No. & $\begin{array}{c}\text { Gestation at } \\
\text { diagnosis (wk) }\end{array}$ & $\begin{array}{c}\text { Diagnosis to } \\
\text { delivery (day) }\end{array}$ & $\begin{array}{c}\text { Birth weights } \\
\text { (gr / gr) }\end{array}$ & $\begin{array}{c}\text { Birth weight } \\
\text { difference: gr (\%) }\end{array}$ & $\begin{array}{c}\text { Outcome of } \\
\text { pregnancy }\end{array}$ \\
\hline 1 & 21 & 5 & $550 / 500$ & 50 (9) & NND / NND \\
2 & 21 & 4 & $540 / 480$ & $60(11)$ & NND / NND \\
3 & 22 & 1 & $600 / 550$ & $50(8)$ & NND / NND \\
4 & 25 & 6 & $720 / 550$ & $170(23)$ & NND / IUD \\
5 & 25 & 1 & $750 / 600$ & $150(20)$ & NND / NND \\
6 & 25 & 17 & $860 / 790$ & $70(8)$ & NND / NND \\
7 & 27 & 6 & $940 / 820$ & $120(13)$ & NND / NND \\
8 & 31 & 10 & $1650 / 900$ & $750(45)$ & LB / IUD \\
9 & 32 & 2 & $1150 / 900$ & $250(22)$ & LB / IUD \\
10 & 33 & 1 & $2000 / 1500$ & $500(25)$ & LB / LB \\
11 & 33 & 15 & $2490 / 1370$ & $1120(45)$ & LB / LB \\
\hline
\end{tabular}

Note: IUD, Intrauterine dead fetus at diagnosis; NND, neonatal dead; LB, live birth

Table 2

The Cases of TTTS at Diagnosis, Interval of Diagnosis to Delivery and Fetal Outcome with Amniodrenage

\begin{tabular}{lccccc}
\hline Case No. & $\begin{array}{c}\text { Gestation at } \\
\text { diagnosis (wk) }\end{array}$ & $\begin{array}{c}\text { Diagnosis to } \\
\text { delivery (day) }\end{array}$ & $\begin{array}{c}\text { Birth weights } \\
\text { (gr / gr) }\end{array}$ & $\begin{array}{c}\text { Birth weight } \\
\text { difference: gr (\%) }\end{array}$ & $\begin{array}{c}\text { Outcome of } \\
\text { pregnancy }\end{array}$ \\
\hline 1 & 19 & 7 & $460 / 420$ & 40 (8) & NND / NND \\
2 & 20 & 32 & $900 / 750$ & $150(16)$ & NND / NND \\
3 & 21 & 26 & $700 / 630$ & $70(10)$ & NND / NND \\
4 & 21 & 19 & $650 / 590$ & $60(9)$ & NND / NND \\
5 & 22 & 1 & $600 / 540$ & $60(10)$ & NND / NND \\
6 & 27 & 6 & $900 / 820$ & $80(8)$ & NND / NND \\
7 & 27 & 35 & $1650 / 1420$ & $230(14)$ & LB / LB \\
8 & 31 & 2 & $1350 / 1100$ & $250(18)$ & LB / LB \\
9 & 33 & 1 & $1950 / 1600$ & $350(18)$ & LB / LB \\
10 & 34 & 3 & $2630 / 1850$ & $780(30)$ & LB / LB
\end{tabular}

Note: IUD, Intrauterine dead fetus at diagnosis; NND, neonatal dead; LB, live birth

removal of $1500 \mathrm{ml}$ (range 500 to $2500 \mathrm{ml}$ ) after uterine contractions ceased. The mean interval between initial examination and delivery was 13 days (range 1 to 35 days). Of the six cases before 28 weeks, five aborted, one had chorioamnionitis and one case diagnosed at $27^{+3}$ weeks delivered a live birth at $32^{+3}$ weeks. The four cases after 28 weeks all delivered live births.

After 28 weeks in four cases followed without intervention and in four cases with amniodrenage, all live fetuses at initial examination were born alive. Before 28 weeks, seven cases without treatment were aborted, one case out of six treated with amniodrenage delivered a live birth. In three cases without intervention $(25,31,32$ weeks) one twin was dead at diagnosis, all were donor and two surviving co-twin (31, 32 weeks) delivered live births.

Eighty five per cent of live births were admitted to the neonatal care unit. Neurological follow up ranging from 6 to 18 months was available for 14 babies out of 16 . A total of 14 babies, six in the natural follow-up group and eight in the amniodrenage group, were normal at follow-up.

\section{$\overline{\text { Discussion }}$}

We found that the survival rate in the natural follow-up group after 28 weeks was similar and comparable to the amniodrenage group. Before 28 weeks, all cases in the natural group and the amniodrenage group except one aborted. Although for untreated cases of TTTS diagnosed before 28 weeks, a mortality rate as high as $100 \%$ has been reported (Chescheir \& Seeds, 1988; Pretorius et al., 1988; Patten et al., 1989; Urig et al., 1990), results of most recent studies of expectant management (Bergella \& Kaufmann, 2001) have shown an improvement of the survival rate by up to $50 \%$, overall $30 \%$ (Table 3 ).

Bergella et al. (2001) reviewed the literature comparing the result of TTTS cases with natural follow-up and reported a $27 \%$ survival rate before 28 weeks. The same increase in perinatal survival has been observed in studies of treatment with amniodrenage or laser (Mari et al., 2001; Quintero et al., 2001; Skupski et al., 2002). Our results did not agree with this improvement. This may be due to different diagnostic criteria or variable clinic presentation of TTTS 
Table 3

Natural Fetal Outcome of TTTS $<28$ wk Without Intervention in the Literature.

\begin{tabular}{lc}
\hline Author & Survival rate* \\
\hline Weir et al., 1979 & $0 / 16$ \\
Witmann et al.,1981 & $0 / 4$ \\
Elejalde et al., 1983 & $0 / 2$ \\
Chescheir \& Seeds, 1988 & $0 / 4$ \\
Pretorius et al., 1988 & $1 / 14$ \\
Brown et al., 1989 & $1 / 8$ \\
Patten et al., 1989 & $3 / 48$ \\
Urig et al., 1990 & $0 / 10$ \\
Gonsoulin et al., 1990 & $6 / 20$ \\
Mahony et al., 1990 & $2 / 10$ \\
Saunders et al., 1992 & $3 / 10$ \\
Bromley et al., 1992 & $10 / 14$ \\
Dennis et al., 1997 & $6 / 8$ \\
Berghella et al., 2001 & $4 / 10$ \\
Total & $36 / 178$ \\
\hline
\end{tabular}

Note: * number of live birth / number of fetus

including only mild to moderate cases in previous studies. The cases we reported here had polyhydramnios in one sac and stuck twin in the other sac, and were accepted as severe TTTS and admitted with no regular follow-up. In addition, in eight cases we did observe the patients with premature contraction or labour at initial examination. In these cases, despite intensive tocolytic treatment, premature labour had occurred. This may have contributed to the high mortality rates. Sebire et al. (1998), quoted a 40\% survival rate for TTTS pregnancies treated with serial amniocentesis and suggested that the inclusion of pregnancies with mild to moderate condition that may not need any therapy could account for the apparent improvement up to $70 \%$ in survival rate in amniodrenage in the last decade.

In the literature there are no results of randomised studies comparing the effects of treatment and natural follow-up. Skupski et al. (2001), did not find any difference between treatment and control groups regarding the interval of diagnosis to delivery, although an insufficient number of cases were reported (Skupski et al., 2001).

In our experience, following the development of acute polyhydramnios in MCDA twin pregnancies before 28 weeks and presenting with premature uterine contraction, all cases aborted despite tocolytic treatment. After 28 weeks, the results of expectant management seem to be the same for the treatment group and a follow-up without intervention appears to be an acceptable choice. The cases of TTTS before 28 weeks, especially presenting in midsecond trimester have a poor prognosis and have to be discussed with parents accordingly.

In TTTS, up to $30 \%$ of cases report major neurological sequelae (Haverkamp et al., 2001). Mari et al. (2000) reported $4.7 \%$ cerebral palsy, in two infants out of 42 . We did not find any major neurological sequelae in 14 babies including two babies born with a dead co-twin. This may be because all live births have occurred after 32 weeks.

In conclusion, mortality of TTTS before 28 weeks is very high and clinically the onset of TTTS in mid-second trimester with premature uterine contraction must be accepted as a poor prognostic sign and this may help with counseling of parents regarding treatment options and natural follow-up.

\section{References}

Bajoria, R., Wigglesworth, J., \& Fisk, N. M. (1995). Angioarchitecture of monochorionic placentas in relation to the twin-twin transfusion syndrome. American Journal of Obstetrics and Gynecology, 172, 856-863.

Berghella, V., \& Kaufmann, M. (200). Natural history of twin-twin transfusion syndrome. Journal of Reproductive Medicine, 46(5), $480-484$

Bromley, B., Frigoletto, F. D. Jr., Estroff, J. A., et al. (1992). The natural history of oligohydramnios/polyhydramnios sequence in monochorionic diamniotic twins. Ultrasound in Obstetrics \& Gynecology, 2, 317-320.

Brown, D. L., Benson, C. B., Driscoll, S. G., et al. (1989). Twintwin transfusion syndrome: Sonographic findings. Radiology, 170, 61-63.

Chescheir, N. C., \& Seeds, J. W. (1988). Polyhydramnios and oligohydramnios in twin gestations. Obstetrics \& Gynecology, $71,882-884$.

Dennis, L. G., \& Winkler, C. L. (1997). Twin-twin transfusion syndrome: Aggressive therapeutic amniocentesis. American Journal of Obstetrics and Gynecology, 177, 342-349.

Derom, R., Derom, C., \& Vlietinck, R. (1996). Placentation. In L. G. Keith, E. Papiernik, D. M. Keith, \& B. Luke (Eds.), Multiple pregnancy (pp. 113-128). London: Parthenon Press.

Elejalde, B. R., de Elejalde, M. M., Wagner, A. M., et al. (1983). Diagnosis of twin to twin transfusion syndrome at 18 weeks of gestation. Journal of Clinical Ultrasound, 11, 442-446.

Gonsoulin, W., Moise, K. J. Jr., Kirshon, B., et al. (1990). Outcome of twin-twin transfusion syndrome diagnosed before 28 weeks of gestation. Obstetrics \& Gynecology, 75, 214-246.

Haverkamp, F., Lex, C., Hanisch, C., Fahnenstich, H., \& Zerres, K. (2001). Neurodevelopmental risks in twin to twin transfusion syndrome: Preliminary findings. European Journal of Paediatric Neurology, 5(1), 21-27.

Johnson, J. R., Rossi, K. Q., \& Ö'Shaughnessy, R. W. (2001). Amnioreduction versus septostomy in twin-twin transfusion syndrome. American Journal of Obstetrics and Gynecology, 185(5), 1044-1047.

Mahony, B. S., Petty, C. N., Nyberg, D. A., et al. (1990). The "stuck twin" phenomenon: Ultrasonographic findings, pregnancy outcome and management with serial amniocenteses. American Journal of Obstetrics and Gynecology, 163, 1513-1522.

Mari, G., Roberts, A., Detti, L., Kovanci, E., Tefos, T., BahadoSingh, R. O., et al. (2001). Perinatal morbidity and mortality rates in severe twin-twin transfusion syndrome: Results of the International Amnioreduction Registry. American Journal of Obstetrics and Gynecology, 185(3), 708-715.

Patten, R. M., Mack, L. A., Harvey, D., Cyr, D. R., \& Pretorius, D. H. (1989). Disparity of amniotic fluid volume and fetal 
size: Problem of the stuck twin-U.S. studies. Radiology, 172, 153-157.

Pretorius, D. H., Manchester, D., Barkin, S., Parker, S., \& Nelson, T. R. (1988). Doppler ultrasound of twin-twin transfusion syndrome. Journal of Ultrasound in Medicine, 7, 117-124.

Quintero, R. A., Bornick, P. W., Allen, M. H., \& Johnson, P. K. (2001). Selective laser photocoagulation of communicating vessels in severe twin-twin transfusion syndrome in women with an anterior placenta. Obstetrics \& Gynecology, 97(3), 477-481.

Saunders, N. J., Snijders, R. J. M., \& Nicolaides, K. H. (1990). Therapeutic amniocentesis in twin-twin transfusion syndrome appearing in the second trimester of pregnancy. (1992). American Journal of Obstetrics and Gynecology, 166, 820-824.
Sebire, N. J., D'Ercole, C., Carvelho, M., et al. (1998). Inter-twin membrane folding in monochorionic pregnancies. Ultrasound in Obstetrics \& Gynecology, 11, 325-327.

Skupski, D. W., Gurushanthaiah, K., \& Chasen, S. (2002). The effect of treatment of twin-twin transfusion syndrome on the diagnosis-to-delivery interval. Twin Research, 5(1), 1-4.

Urig, M. A., Clewell, W. H., \& Elliott, J. P. (1990). Twin-twin transfusion syndrome. Obstetrics \& Gynecology, 163, 1522-1526.

Weir, P. E., Ratten, G. J., \& Beischer, N. A. (1979). Acute polyhydramnios: A complication of monozygous twin pregnancy. British Journal of Obstetrics and Gynaecology, 86, 849-853.

Wittman, B. K., Baldwin, V. J., \& Nichol, B. (1981). Antenatal diagnosis of twin transfusion syndrome by ultrasound. Obstetrics \& Gynecology, 58, 123-127. 